\title{
Article \\ Cosmetics Utilization Practice in Jigjiga Town, Eastern Ethiopia: A Community Based Cross-Sectional Study
}

\author{
Arebu I. Bilal ${ }^{1}$, Zelalem Tilahun ${ }^{1}$, Tariku Shimels ${ }^{2, *}$, Yewubdar B. Gelan ${ }^{3}$ and \\ Ebrahim D. Osman ${ }^{4}$ \\ 1 Department of Pharmaceutics and Social Pharmacy, School of Pharmacy, College of Health Sciences, \\ Addis Ababa University, Addis Ababa, Ethiopia; arebu.issa@aau.edu.et (A.I.B.); zelatilahun@gmail.com (Z.T.) \\ 2 Medical Logistics and Pharmaceutical Services Coordination, Federal Police Commission Health Service \\ Directorate, Addis Ababa, Ethiopia \\ 3 Department of Pharmacology, School of Medicine, College of Health Sciences, Addis Ababa University, \\ Addis Ababa, Ethiopia; yewub2007@gmail.com \\ 4 Department of Pharmacy, Jigjiga Health Sciences College, Jigjiga, Ethiopia; ebraadaa@yahoo.com \\ * Correspondence: tarphar2008@gmail.com; Tel.: +251-912-47-12-23
}

Academic Editor: Enzo Berardesca

Received: 20 August 2016; Accepted: 24 November 2016; Published: 1 December 2016

\begin{abstract}
The trend of cosmetics utilization has increased globally; however, the exact amount of usage is not researched well. Lack of population awareness on proper use of cosmetics, particularly in developing countries, causes a prominent health challenge. Therefore, this study was conducted to assess the cosmetics utilization practices in Jigjiga town, Eastern Ethiopia. A community based cross-sectional study, using a semi-structured questionnaire, was used to assess factors associated with cosmetics use. Of the 559 participants, $93 \%$ used at least one type of cosmetics in the two weeks prior to the survey. The most commonly used products were body creams and lotions $(68 \%)$, shampoos and conditioners (35\%), and deodorants and perfumes (29\%). Being single, female, and in the age group of 18-20 years increased the odds of cosmetics utilization. However, being in primary school and being self-employed showed a less likely use of cosmetics. Two hundred forty-seven (44\%) of the interviewed household members reported that they use traditional herbal cosmetics. A higher likelihood of traditional herbal cosmetics use was observed in the age group of 18-20 years. This study indicated that the community in Jigiga town use different types of cosmetics. Education, occupation, marital status, age, and gender were all important factors that determined the use of cosmetics in the study area.
\end{abstract}

Keywords: cosmetics; cosmetic types; Ethiopia; Jigjiga town; traditional herbal cosmetics

\section{Introduction}

Cosmetics are defined as substances or preparations intended to be applied on various external parts of the human body with the purpose of cleaning, perfuming, changing appearance, correcting body odors, protecting or keeping those body parts in good condition [1]. These substances include perfumes, skin creams, lotions, deodorants, makeup, hair preparations, and others [2,3].

Wearing cosmetics is one of the most common human behaviors and is present across different cultures [4]. In modern societies, the use of cosmetics by females to alter facial appearance is nearly universal [5]. Studies indicate that female faces have greater facial contrast than male faces and there is a positive relationship between facial contrast and facial attractiveness [6]. Moreover, perceptions of attractiveness increase when cosmetics are applied, and when wearing cosmetics, females provide higher estimates of their own attractiveness [7,8]. Applying cosmetics also increases perceptions of 
traits related to attractiveness, with wearers perceived as healthier and from a higher socioeconomic background [9]. Cosmetics can be used to mark the culture, class, religion, or other social group to which a person belongs. They can also be used to indicate status, rank, or wealth within a group, as well as other personal information, such as age, gender, or reproductive status [6]. Studies have shown that cosmetic use seems to be linked with ages greater than 18 years [5], female gender [10], nature of career, and also the geographical factors where people are living [11]. Cosmetics use also has psychological implications such as decreasing anxiety and increasing self-confidence [12].

Scholars have also used social comparison and self-discrepancy theories to explain people's motivations for cosmetics usage. In social comparison theory, people are concerned with their own physical appearance and compare themselves to others or with media images which may lead to negative self-perceptions and lowered self-esteem. In such instances, individuals are then motivated to engage in cosmetics use [13]. Self-discrepancies occur when there is a mismatch, or inconsistency, between aspects of the self [14]. Discrepancies between the attractiveness of the actual and the ideal self can lead to lower body image and lower self-esteem [15]. People may apply cosmetics to close the gap between their actual and their ideal selves.

The value of the global cosmetics industry reached USD 465 billion in 2014 and is expected to reach USD 675 billion by 2020 [16]. Though cosmetics usage is an increasing trend across the globe, some users are not very concerned about the implications of cosmetics to their body health including such factors as skin and physical outlook. This condition, coupled with the lack of proper channels of communication for reporting cosmetic related adverse effects and product modification, makes cosmetic products rank among the top causes of toxic exposure [10,17-19]. To compensate for this, cosmetics consumers are strongly encouraged to adhere to the following safety tips: reading labels, following all directions, heeding all warnings, washing hands before using the product, not sharing makeup, keeping the containers clean and tightly closed when not in use and protecting them from temperature extremes, and throwing away cosmetics if there are changes in color or smell [20].

Documenting cosmetic utilization practices is expected to have a significant role in increasing public awareness and proper utilization among community members. Therefore, this study was done to assess the cosmetic utilization practices in Jigjiga town, Eastern Ethiopia.

\section{Methods}

\subsection{Study Setting and Design}

A community based cross-sectional survey was conducted in Jigjiga town, Eastern Ethiopia, from May to June 2014. Jigjiga town is the capital town of the Somalia National Regional State of Ethiopia. The town has ten kebeles (the smallest administrative units).

\subsection{Study Population}

Among the ten kebeles found in the town, four of them were selected via simple random sampling. The number of households (HHs) included from each selected kebele was determined based on the proportion of the population in the kebeles. The sample of HHs in each kebele was identified using systematic random sampling techniques where every third $\mathrm{HH}$ was taken until the required size was met in each kebele. One eligible adult HH member was randomly selected from each household. Adults who were aged 18 or older, lived in the town for at least six months prior to the data collection, and gave informed consent were included in the study.

\subsection{Variables}

Potential associated factors for the outcome measure were: socio-demographic variables, duration and frequency of use, type and number of cosmetics used, cosmetics selection criteria, concomitant use of herbal remedies, and purpose of use and way of administration (see Supplementary materials for the full questionnaire). 


\subsection{Data Source and Collection Procedure}

In this study, participants were interviewed in Ethiopia since previous research has found that online samples are not representative of populations in developing countries [21]. A pre-tested, semi-structured questionnaire was used for the data collection. The questionnaire was prepared in English and translated into the local language. One eligible adult was randomly selected from each household. Data was collected by four trained recruits who speak the local language fluently and who have health science backgrounds. The whole data collection process was supervised by the principal investigators.

\subsection{Sample Size Calculation}

A single population proportion formula was used to calculate the minimum sample size required for the study. Since there was no prior community based study that showed the prevalence of cosmetics use in the previous two weeks, we took the proportion to be $50 \%$, standard normal deviation of 1.96 (at 95\% confidence interval), and 4\% degree of freedom. The final sample size was 601 .

\subsection{Operational Definitions}

Traditional herbal cosmetics refer to homemade cosmetics prepared from indigenous herbs in the study area. On the other hand, modern cosmetics refer to those manufactured, packaged and labeled by international or national companies and commercially available in local markets.

\subsection{Ethical Consideration}

The Institutional Ethical Review Board of the School of Pharmacy, Addis Ababa University gave permission to conduct the survey. Discussions about the aim and purpose of the survey were undertaken with the Jigjiga Woreda Health Office and local community leaders, and permission was obtained accordingly. Finally, verbal consent was obtained from each study participant before conducting the interview.

\subsection{Data Entry and Analysis}

Descriptive statistics were used to summarize the nature and frequency of cosmetic use. Bivariate and multivariate logistic regression analyses were employed to investigate cosmetic utilization associated factors. Variables with $p<0.20$ within the bivariate analyses were included in the multivariate logistic model. The Statistical Package for Social Sciences (SPSS) software version 20 was used for the analysis. Statistical significance was determined at $p$ values of $\leq 0.05$.

\section{Results}

\subsection{Socio-Demographic Characteristics of Respondents}

From the total $601 \mathrm{HHs}$ approached for the study, only 559 were available and successfully interviewed which gives a response rate of $93 \%$. The mean age of the respondents was 21.8 years $(\mathrm{SD} \pm 2.7)$ and more than half of them $(56 \%)$ were in the age group of $18-20$ years. Four hundred twenty-four (76\%) were female and $477(85 \%)$ were Somali by ethnicity. Four hundred thirty-seven $(78 \%)$ of the respondents were single. More than half $(53 \%)$ had completed secondary school education. Two thirds (66\%) of the participants were students and 265 (47\%) participants earn an average monthly income of below 1000 Ethiopian Birr (ETB) (Table 1). 
Table 1. Socio-demographic characteristics of respondents in Jigjiga town, Somali Regional State, Ethiopia; June 2014 ( $n=559)$.

\begin{tabular}{|c|c|c|}
\hline \multicolumn{2}{|l|}{ Variables } & $n(\%)$ \\
\hline \multirow{3}{*}{ Age } & $18-20$ & $310(56)$ \\
\hline & $21-30$ & $219(39)$ \\
\hline & $\geq 31$ & $30(5)$ \\
\hline \multirow{2}{*}{ Gender } & Male & $135(24)$ \\
\hline & Female & $424(76)$ \\
\hline \multirow{3}{*}{ Religion } & Muslim & $516(92)$ \\
\hline & Orthodox & $36(7)$ \\
\hline & Others * & $7(1)$ \\
\hline \multirow{4}{*}{ Ethnicity } & Somali & $477(85)$ \\
\hline & Oromo & $30(5)$ \\
\hline & Amhara & $44(8)$ \\
\hline & Gurage & $8(2)$ \\
\hline \multirow{2}{*}{ Marital Status } & Single & $437(78)$ \\
\hline & Married & $122(22)$ \\
\hline \multirow{4}{*}{ Educational Status } & Illiterate & $54(10)$ \\
\hline & Primary school & $92(16.5)$ \\
\hline & Secondary School & $298(53)$ \\
\hline & College and University & $115(20.5)$ \\
\hline \multirow{4}{*}{ Occupation } & House wife & $64(11)$ \\
\hline & Student & $368(66)$ \\
\hline & Self employed & $34(6)$ \\
\hline & Others ** & $93(17)$ \\
\hline \multirow{4}{*}{ Average Monthly Income in ETB * } & $\leq 1000$ & $265(47)$ \\
\hline & $1001-2000$ & $151(27)$ \\
\hline & $2001-3000$ & $88(16)$ \\
\hline & $\geq 3001$ & $55(10)$ \\
\hline
\end{tabular}

\subsection{Cosmetic Utilization Status}

Of the 559 study participants, 521 (93\%) used cosmetics in the past two weeks. Among these, $280(54 \%)$ of the users reported that they use it for "cleansing" purposes. The most commonly used products were "body creams and lotions", "shampoos and conditioners", and "deodorants and perfumes" as cited by $355(68 \%), 182(35 \%)$, and $153(29 \%)$ of the users, respectively.

Seventy percent of the participants claimed that "quality" is their main selection criterion. Among the quality indicators mentioned by the users were country of production (209 participants, $40 \%$ ), media advertisement (144 participants, $28 \%$ ), and popularity ( 80 participants, $15 \%$ ). From the users who claimed county of production as an indicator of quality, $121(58 \%)$ showed preference for cosmetics produced in India. The majority of the respondents (324 participants, $62 \%$ ) used cosmetics products on a daily basis, and $387(74 \%)$ of them used their cosmetics products more than once a day.

Three hundred fifty-three $(68 \%)$ of the respondents bought their cosmetics products from supermarkets and only $40(8 \%)$ purchased them from pharmacies or drug shops. Four hundred sixty-two $(89 \%)$ of the respondents had a habit of reading labels written on cosmetics products, of whom the majority (39\%) read the expiry date and only $41(6 \%)$ read the special remarks. Three hundred forty-five (75\%) of the respondents reported that they always read labels when purchasing a product (Table 2). 
Table 2. Cosmetics utilization practices among respondents in Jigjiga town, Somali Regional State, Ethiopia; June $2014(n=559)$.

\begin{tabular}{|c|c|}
\hline Variable Category and Options & Frequency $n(\%)$ \\
\hline \multicolumn{2}{|c|}{ Cosmetics use in the past two weeks } \\
\hline Yes & $521(93)$ \\
\hline No & $38(7)$ \\
\hline \multicolumn{2}{|l|}{ Purpose of use $(n=521)$} \\
\hline Cleansing & $280(54)$ \\
\hline Beautification & $100(19)$ \\
\hline Protection & $76(14)$ \\
\hline Medication & $29(6)$ \\
\hline Whitening & $24(5)$ \\
\hline Anti-aging & $6(1)$ \\
\hline Hair coloring & $6(1)$ \\
\hline \multicolumn{2}{|l|}{ Type of cosmetics used $(n=521)^{*}$} \\
\hline Body creams and lotions & $355(68)$ \\
\hline Shampoos and conditioners & $182(35)$ \\
\hline Deodorants and perfumes & $153(29)$ \\
\hline Face powder & $90(17.3)$ \\
\hline Lipsticks & $89(16)$ \\
\hline Hair cosmetics & $86(16.5)$ \\
\hline Tooth paste & $78(15)$ \\
\hline Eye makeup & $74(14.2)$ \\
\hline Skin color & $54(10.4)$ \\
\hline Nail polish & $39(7.5)$ \\
\hline \multicolumn{2}{|l|}{ Main criterion for selection } \\
\hline Quality of the product & $392(75)$ \\
\hline Affordability of the price & $94(18)$ \\
\hline Easily accessible in the market & $35(7)$ \\
\hline \multicolumn{2}{|l|}{ Quality indicators } \\
\hline Country of production & $209(40)$ \\
\hline Advertised on media & $144(28)$ \\
\hline Most of the people use & $80(15)$ \\
\hline Brand of the product & $51(10)$ \\
\hline High price of the product & $37(7)$ \\
\hline \multicolumn{2}{|l|}{ Country of origin $(n=209)$} \\
\hline Indian & $121(58)$ \\
\hline Western & $46(22)$ \\
\hline Chinese & $24(11)$ \\
\hline Local & $18(9)$ \\
\hline \multicolumn{2}{|c|}{ Frequency of use (general) $(n=521)$} \\
\hline Daily & $324(62)$ \\
\hline For special occasions & $109(21)$ \\
\hline Sometimes & $88(17)$ \\
\hline \multicolumn{2}{|l|}{ Frequency of use (daily) $(n=521)$} \\
\hline Once & $134(25.7)$ \\
\hline Twice & $196(37.6)$ \\
\hline Three times & $144(27.7)$ \\
\hline More than three times & $47(9)$ \\
\hline \multicolumn{2}{|l|}{ Common source } \\
\hline Supermarket & $353(68)$ \\
\hline Shop & $128(24)$ \\
\hline Pharmacy or drug shop & $40(8)$ \\
\hline \multicolumn{2}{|l|}{ Read cosmetics related information } \\
\hline Yes & $462(89)$ \\
\hline No & $59(11)$ \\
\hline
\end{tabular}


Table 2. Cont.

\begin{tabular}{lc}
\hline Variable Category and Options & Frequency $\boldsymbol{n}(\mathbf{\%})$ \\
\hline If yes, type of information read & $164(22)$ \\
Brand name & $287(39)$ \\
Expiry date & $189(26)$ \\
Ingredients & $53(7)$ \\
Use instruction & $41(6)$ \\
Special remarks & \\
\hline If yes, when do you read information & $345(75)$ \\
Always when purchasing a product & $93(20)$ \\
Only when purchasing a product for the first time & $25(5)$ \\
When observing some kind of side effect or effectiveness of the product declined & \\
\hline Which instruction of use do you think is one should strictly follow * & $420(80.7)$ \\
Washing your hands and the respective body part before application of cosmetics & $119(22.9)$ \\
Cleansing body parts before sleeping to remove cosmetics & $61(11.7)$ \\
Avoiding exposure to sun light for a lengthy period & \\
\hline
\end{tabular}

* More than one option is possible.

\subsection{Factors Associated with Cosmetics Utilization}

The logistic regression analysis revealed that certain socio-demographic variables have association with the utilization of a cosmetics product. Being single increased the odds of cosmetics utilization four times as compared with those married (adjusted odds ratio (AOR) = 4.66; 95\% confidence interval (CI) (1.91-11.34)). Educational status has shown an important association with cosmetics utilization in that those with primary education were less likely to be cosmetic users as compared to those who completed college and university (AOR $=0.24 ; 95 \% \mathrm{CI}(0.06-0.84))$. On the other hand, being self-employed was found to be negatively associated with the use of any type of cosmetics $(\mathrm{AOR}=0.14 ; 95 \% \mathrm{CI}(0.04-0.55))$. Other variables like gender and average monthly income did not show significant association with cosmetics utilization (Table 3).

Table 3. Factors associated with cosmetics utilization among respondents in Jigjiga town, Somali Regional State, Ethiopia; June 2014 ( $n=559,95 \%$ confidence interval $(\mathrm{CI})$ ). COR = crude odd ratio. AOR = adjusted odds ratio.

\begin{tabular}{cccccc}
\hline \multirow{2}{*}{ Determinants } & \multicolumn{2}{c}{ Utilization Status } & \multicolumn{2}{c}{ 95\% CI } \\
\cline { 2 - 5 } & & Yes & No & COR & AOR \\
\hline \multirow{2}{*}{ Gender } & Male & 124 & 11 & $0.77(0.37-1.59)$ & $0.92(0.38-2.21)$ \\
& Female & 397 & 27 & 1.00 (reference) & 1.00 (reference) \\
\hline \multirow{2}{*}{ Marital Status } & Single & 418 & 19 & $* 4.06(2.07-7.94)$ & $* 4.66(1.91-11.34)$ \\
& Married & 103 & 19 & 1.00 (reference) & 1.00 (reference) \\
\hline \multirow{4}{*}{ Educational Status } & Illiterate & 47 & 7 & $0.37(0.12-1.16)$ & $0.52(0.13-2.06)$ \\
& Primary School & 80 & 12 & $0.37(0.13-1.02)$ & $* 0.24(0.06-0.84)$ \\
& Secondary School & 285 & 13 & $1.21(0.45-3.26)$ & $0.73(0.21-2.50)$ \\
& College and University & 109 & 6 & 1.00 (reference) & 1.00 (reference) \\
\hline \multirow{4}{*}{ Occupation } & House wife & 56 & 8 & $0.32(0.09-1.09)$ & $1.05(0.24-4.54)$ \\
& Student & 351 & 17 & $0.93(0.31-2.83)$ & $1.17(0.30-4.68)$ \\
& Self Employed & 25 & 9 & $* 0.13(0.04-0.44)$ & $* 0.14(0.04-0.55)$ \\
Average Monthly & Others & 89 & 4 & 1.00 (reference) & 1.00 (reference) \\
Income in ETB & $\leq 1000$ & 247 & 18 & $1.08(0.35-3.31)$ & $0.38(0.09-1.55)$ \\
& $1001-2000$ & 141 & 10 & $1.11(0.33-3.68)$ & $0.44(0.10-1.89)$ \\
& $2001-3000$ & 82 & 6 & $1.07(0.29-3.98)$ & $1.19(0.26-5.37)$ \\
& $\geq 3001$ & 51 & 4 & 1.00 (reference) & 1.00 (reference) \\
\hline
\end{tabular}

* Significant at $p \leq 0.05$ multivariate logistic regression. 


\subsection{Factors Associated with Traditional Herbal Cosmetics Use}

Two hundred forty-seven (44\%) of the interviewed household members reported that they use traditional herbal cosmetics. Certain socio-demographic variables were associated with the use of traditional herbal cosmetics. A higher likelihood of traditional herbal cosmetics usage was observed in the age group of $18-20$ years (AOR $=2.67 ; 95 \% \mathrm{CI}(1.03-6.92)$ ).

In contrast, male gender $(\mathrm{AOR}=0.63 ; 95 \% \mathrm{CI}(0.40-0.99))$, being a housewife $(\mathrm{AOR}=0.39 ; 95 \% \mathrm{CI}$ $(0.17-0.91))$, and being self-employed (AOR $=0.34,95 \% \mathrm{CI}(0.12-0.91)$ ) were found to be negative predictors of traditional herbal cosmetics utilization while other variables such as educational status and average monthly income did not show any significant association (Table 4).

Table 4. Factors associated with traditional herbal cosmetics use among respondents in Jigjiga town, Somali Regional State, Ethiopia; June 2014 ( $n=559,95 \%$ CI).

\begin{tabular}{|c|c|c|c|c|c|}
\hline \multirow{2}{*}{\multicolumn{2}{|c|}{ Determinants }} & \multicolumn{2}{|c|}{ Use Status } & \multicolumn{2}{|c|}{$95 \% \mathrm{CI}$} \\
\hline & & Yes & No & COR & AOR \\
\hline \multirow{3}{*}{ Age } & $18-20$ & 144 & 166 & * $2.39(1.03-5.52)$ & * $2.67(1.03-6.92)$ \\
\hline & $21-30$ & 95 & 124 & $2.12(0.90-4.94)$ & $2.38(0.92-6.13)$ \\
\hline & $\geq 31$ & 8 & 22 & 1.00 (reference) & 1.00 (reference) \\
\hline \multirow[b]{2}{*}{ Gender } & Male & 46 & 89 & *0.57 (0.38-0.86) & *0.63 (0.40-0.99) \\
\hline & Female & 201 & 223 & 1.00 (reference) & 1.00 (reference) \\
\hline \multirow[b]{2}{*}{ Marital Status } & Single & 195 & 242 & $1.10(0.72-1.63)$ & $0.80(0.46-1.40)$ \\
\hline & Married & 52 & 70 & 1.00 (reference) & 1.00 (reference) \\
\hline \multirow{4}{*}{ Educational Status } & Illiterate & 21 & 33 & $0.96(0.49-1.85)$ & $1.57(0.67-3.70)$ \\
\hline & Primary School & 45 & 47 & $1.44(0.83-2.50)$ & $1.93(0.96-3.88)$ \\
\hline & Secondary School & 135 & 163 & $1.24(0.80-1.92)$ & $1.44(0.81-2.58)$ \\
\hline & College and University & 46 & 69 & 1.00 (reference) & 1.00 (reference) \\
\hline \multirow{4}{*}{ Occupation } & House wife & 26 & 38 & $0.73(0.38-1.39)$ & * $0.39(0.17-0.91)$ \\
\hline & Student & 169 & 199 & $0.91(0.57-1.43)$ & $0.68(0.35-1.33)$ \\
\hline & Self Employed & 7 & 27 & * $0.01(0.11-0.70)$ & * $0.34(0.12-0.91)$ \\
\hline & Others & 45 & 48 & 1.00 (reference) & 1.00 (reference) \\
\hline \multirow{4}{*}{$\begin{array}{l}\text { Average Monthly } \\
\text { Income in ETB }\end{array}$} & $\leq 1000$ & 109 & 156 & $0.90(0.50-1.62)$ & $0.74(0.38-1.47)$ \\
\hline & $1001-2000$ & 77 & 74 & $1.34(0.72-2.50)$ & $1.12(0.56-2.26)$ \\
\hline & 2001-3000 & 37 & 51 & $0.94(0.47-1.85)$ & $1.03(0.49-2.17)$ \\
\hline & $\geq 3001$ & 24 & 31 & 1.00 (reference) & 1.00 (reference) \\
\hline
\end{tabular}

* Significant at $p \leq 0.05$ multivariate logistic regression.

\section{Discussion}

Half of the cosmetics users in this study reported that they utilize cosmetics for "cleansing" purposes. This might be to cope with the dust and excessive sweating due to the hot and windy environment. Nevertheless, other studies have documented that "feeling beautiful" and "improved self-confidence" were among the common reasons for cosmetics use [7,8,22]. "Body creams and lotions" and "shampoos and conditioners" were reported to be the top utilized cosmetics types in the study area. This is expected as cleansing and moisturizing the face are procedures which generally require performance multiple times per day. The other possible explanation for why "body creams and lotions" and "shampoos and conditioners" were reported as the top utilized cosmetics is that they are utilized by both genders. Furthermore, "body creams and lotions" are among the top utilized cosmetics as most of the subjects belong to an age group generally troubled by problems associated with acne prone skin. Findings across the country have also mentioned that these products were the most utilized $[23,24]$. In contrast, lipsticks, mascara, and liners were the most commonly used among university students in Iran [22].

More than $85 \%$ of the respondents in this study reported that they read information from containers of cosmetics products. Lesser figures of a similar practice were reported in other studies done 
by Meharie et.al and Dibaba et.al in Ethiopia $[23,24]$. Thirty-nine percent of the users read information on expiry dates, followed by those who read information on ingredients of the product $(26 \%)$ and brand name (22\%). In contrast, a report in Mekelle University of Ethiopia revealed that respondents gave greater attention to instructions for use, ingredient content, and brand names [24]. This might initiate a need for community-based awareness-creation on reading the label of cosmetics properly.

The majority of the respondents in our study responded that they use "quality" as criterion for selecting a cosmetic product. However, most of these groups agreed that their common measure of quality is by "the country of production" and "advertisement on media". Nevertheless, a study in India indicated that factors like health care recommendations, quality, and fragrance got greater importance for selection of cosmetic products [25]. The fact that the majority of cosmetics users in this study reported that they prefer Indian products might be because most Indian skin care products are perceived to be derived from herbal and spicy sources [26].

Female gender increases the odds of cosmetics use. This may be due to the fact that cosmetic application increases facial contrast which is positively related with attractiveness and femininity [6]. Similarly, being single and young increased the odds of cosmetics use in the study area. Similar findings were also reported elsewhere [5,25-28]. The drives commonly enumerated for using cosmetics include feeling clean and attractive, increasing sexual stamina, feeling good and sexually active, as well as countering sexual risks [28-30]. Several studies have found that using cosmetics makes women appear healthier, more attractive, and more feminine [7-9,26,30]. Furthermore, cosmetic use may also be linked to success in the work place. Beautiful people of both sexes tend to have a higher earning potential than those who are below-average or average looking $[5,8,9,12,22,31,32]$. This can also be further explained by self-discrepancy and social comparison theories. Self-discrepancy increases among young adults which can lead to motivations for cosmetics usage [33]. Besides, cosmetics use may be influenced by comparisons made both with real people and with media images. Young adults are more susceptible to the effects of media and they often compare themselves with the idealized images presented in advertising [34].

People who were self-employed were found to be less likely to use both modern cosmetics and traditional herbal cosmetics as compared to government workers and the unemployed. Whereas, income level was not important to determine the practice of cosmetics use among the study population, other factors such as leisure time, work behavior, and peer influence might have additive effects in different groups (self-employed vs. government workers or unemployed). On the other hand, being a housewife was negatively associated with traditional herbal cosmetic use. This might be because housewives spend most of their time at home caring for their children. The fact that traditional herbal cosmetics are not available readymade and require more time for preparation may contribute to their low utilization among housewives.

This study included a sufficient sample size which was composed of a variety of socio-demographic characteristics of the respondents. Being at a community level, the results showed the practices of cosmetics use in the region and may serve as a baseline for future studies. Nonetheless, the lack of information on the amount of money spent on the cosmetics products was one of the limitations of this study.

\section{Conclusions}

Being young, female, and single increased the use of cosmetics in the study area which might be related to competition for mates and status in society. Advertisements on media, country of production, and price were used for determining quality of the cosmetics products. Reading labels was found to be high, though the number of people who read instruction for use and special remarks was found to be low. Cosmetics sellers should provide the relevant information to consumers pertaining to application instructions and cautions. In addition, there needs to be a community-based awareness-creation program like health education by the Woreda Health Office to increase consumers' awareness on appropriate cosmetics use. 
Acknowledgments: Our appreciation goes to the people of Jigijga town for their positive response, for sharing their valuable knowledge and time, as well as for their tremendous generosity and hospitality. In addition, the authors would like to acknowledge the data collectors for their tireless efforts during the data collection process.

Author Contributions: Arebu I. Bilal, Ebrahim D. Osman, and Zelalem Tilahun coordinated the data collection; performed data entry and analysis; and wrote the draft manuscript. Arebu I. Bilal, Tariku Shimels, and Yewubdar B. Gelan were involved in the design and development of the data collection instrument and corrected the manuscript writing. All of the authors have read and approved the final manuscript.

Conflicts of Interest: The authors declare no conflict of interest.

\section{Abbreviations}

The following abbreviations are used in this manuscript:

$\begin{array}{ll}\text { AOR } & \text { Adjusted Odds Ratio } \\ \text { COR } & \text { Crude Odds Ratio } \\ \text { ETB } & \text { Ethiopian Birr } \\ \text { HHs } & \text { Households } \\ \text { SD } & \text { Standard Deviation } \\ \text { SPSS } & \text { Statistical Package for Social Sciences }\end{array}$

\section{References}

1. Ethiopian Food, Medicine and Healthcare Administration and Control Authority. Cosmetics and Sanitary Items Directive No. 24; Ethiopian Food, Medicine and Healthcare Administration and Control Authority: Addis Ababa, Ethiopia, 2014. Available online: http://www.fmhaca.gov.et/documents/Cosmetics\%20and\% 20Sanitary\%20Items\%20Directive.pdf (accessed on 28 November 2016).

2. Martin, M. Cosmetics and their relation to drugs. In Encyclopedia of Pharmaceutical Technology; James, S., James, G., Eds.; Marcel Dekker Inc.: New York, NY, USA, 2002; Volume 2, pp. 649-657.

3. Clarence, R. Cosmetics. In The World Book Encyclopedia; Fetzer, S., Ed.; World Book Inc.: Chicago, IL, USA, 1994; Volume 4, pp. 1075-1076.

4. Jablonski, N.G. Skin: A Natural History; University of California Press: Berkeley, CA, USA, 2006.

5. Etcoff, N. Survival of the Prettiest; Doubleday: New York, NY, USA, 1999.

6. Russell, R. Why Cosmetics Work. In The Science of Social Vision; Adams, R.B., Ambady, N., Nakayama, K., Shimojo, S., Eds.; Oxford University Press: Oxford, UK, 2010; pp. 186-204.

7. Cash, T.F.; Dawson, K.; Davis, P.; Bowen, M.; Galumbeck, C. Effects of cosmetics use on the physical attractiveness and body image of American college women. J. Soc. Psychol. 1989, 129, 349-355. [CrossRef]

8. Etcoff, N.L.; Stock, S.; Haley, L.E.; Vickery, S.A.; House, D.M. Cosmetics as a Feature of the Extended Human Phenotype: Modulation of the Perception of Biologically Important Facial Signals. PLoS ONE 2011, 6, e25656. [CrossRef] [PubMed]

9. Nash, R.; Fieldman, G.; Hussey, T.; Lévêque, J.L.; Pineau, P. Cosmetics: They influence more than Caucasian female facial attractiveness. J. Appl. Soc. Psychol. 2006, 36, 493-504. [CrossRef]

10. Mansor, N.; Ali, D.E.M.; Yaacob, M.R. Cosmetic Usage in Malaysia: Understanding of the Major Determinants Affecting the Users. Int. J. Bus. Soc. Sci. 2010, 1, 273-281.

11. Mansor, N. Career Women: The Need for Image Building. As a Culture at a Work Place. In Proceedings of the 2nd Asia Pacific Business Conference, Putrajaya, Malaysia, 10-12 April 2005.

12. Korichi, R.; Pelle-De-Queral, D.; Gazano, G.; Aubert, L.V.M. Why women use makeup? Implication of psychological traits in makeup functions. J. Cosmet. Sci. 2008, 59, 127-137. [PubMed]

13. Lennon, J.L.; Rudd, N.A.; Sloan, B.; Kim, J.S. Attitudes towards gender roles, self-esteem, and body image: Application of a model. Cloth. Text. Res. J. 1999, 17, 191-202. [CrossRef]

14. Higgins, E.T. Self-Discrepancy: A theory relating self and affect. Psychol. Rev. 1987, 94, 319-340. [CrossRef] [PubMed]

15. Jung, J.; Lennon, S.J.; Rudd, N.A. Self-schema or self-discrepancy? Which best explains body image? Cloth. Text. Res. J. 2001, 19, 171-184. [CrossRef]

16. Research and Markets: Global Cosmetics Market 2015-2020. Available online: http:/ /www.businesswire. com/news/home/20150727005524/en/Research-Markets-Global-Cosmetics-Market-2015-2020-Market (accessed on 18 November 2016). 
17. Healthy Cosmetics. Available online: http://www.healthline.com/health/beauty-skin-care-cosmetics\# Overview1 (accessed on 16 November 2016).

18. Cosmetics and Your Health; Department of Dermatology, Georgetown University, National Women's Health Information Center: Washington, DC, USA, 2004. Available online: https:/ /www.umassmed.edu/contentassets / dafad72ef4ba4b3a9e7da596b5c012d8/cosmetics-your-health.pdf (accessed on 13 February 2016).

19. Parkinson, A. Regulation of cosmetics. In Casarett and Doull's Toxicology. The Basic Science of Poison, 5th ed.; McGraw Hill: New York, NY, USA, 1996; pp. 1013-1014.

20. Adverse Reactions to Cosmetics and Skin Care Products. Available online: http://www.dermatiquemd. com/education/adverse-reactions-to-cosmetics-and-skin-careproducts/ (accessed on 18 January 2016).

21. Batres, C.; Perrett, D.I. The influence of the digital divide on face preferences in El Salvador: People without internet access prefer more feminine men, more masculine women, and women with higher adiposity. PLoS ONE 2014, 9, e0155279. [CrossRef] [PubMed]

22. Jalilian, F.; Ahmadpanah, M.; Karimi, M.; Salehi, I.; Vahidinia, A.S.; Emdadi, S. Prevalence and reasons for cosmetic products use among female students in Hamedan universities. J. Dermatol. Cosmet. 2012, 3, 9-15.

23. Meharie, B.G.; Ambaye, A.S.; T/Haymanot, Y.M.; Atnafie, S.A. Cross sectional study on assessment on cosmetics utilization and self reported adverse reactions among Wollo University Dessie Campus Female Students, Dessie, North East Ethiopia. Eur. J. Pharm. Med. Res. 2014, 2, 49-63.

24. Dibaba, H.; Yadesa, D.; Legesse, B.; Shewamene, Z.; W/Gerima, B. Cosmetics Utilization Pattern and Related Adverse Reactions among Female University Students. Int. J. Pharm. Sci. Res. 2013, 4, 997-1004.

25. Selvakumar, M. Analysis of Factors Influencing the Preference for the Selection of Cosmetics Products by the Respondents Using Garrett's Ranking Technique. Indian J. Appl. Res. 2013, 3, 95-96.

26. Gediya, S.K.; Mistry, R.B.; Patel, U.K.; Blessy, M.; Jain, H.N. Herbal Plants: Used as a cosmetics. J. Nat. Prod. Plant Resour. 2011, 1, 24-32.

27. Cong, D. Single women in Amish Society. In Sects, Cults and Spiritual Communities, a Sociological Analysis; Zellner, W., Petrowsky, M., Eds.; Greenwood Publisher Group: Santa Barbara, CA, USA, 1998; pp. 131-140.

28. Fruend, R.M.; Dyne, A.V. Cosmetic Breast Surgery: A Complete Guide on Making the Right Decision-From A to Double D; Da Capo Press: New York, NY, USA, 2004; pp. 1-5.

29. Ng, J.H.; Yeak, S.; Phoon, N.; Lo, S. Cosmetic procedures among youths: A survey of junior college and medical students in Singapore. Singap. Med. J. 2014, 55, 422-426. [CrossRef]

30. Hardon, A.; Idrus, N.I.; Hymans, T.D. Chemical sexualities: The use of pharmaceutical and cosmetic products by youth in South Sulawesi, Indonesia. Reprod. Health Matters 2013, 21, 214-224. [CrossRef]

31. Thomas, F.; Diane, W. Women's use of cosmetics: Psychosocial correlates and consequences. Int. J. Cosmet. Sci. 1982, 4, 1-14.

32. Cox, C.L.; Glick, W.H. Resume evaluations and cosmetics use: When more is not better. Sex Roles 1986, 14, 51-58. [CrossRef]

33. Heidrich, S.M. Self-discrepancy across the life span. J. Adult Dev. 1999, 6, 119-130. [CrossRef]

34. Perloff, R.M. Social Media Effects on Young Women's Body Image Concerns: Theoretical Perspectives and an Agenda for Research. Fem. Forum Rev. Artic. 2014. [CrossRef]

(C) 2016 by the authors; licensee MDPI, Basel, Switzerland. This article is an open access article distributed under the terms and conditions of the Creative Commons Attribution (CC-BY) license (http://creativecommons.org/licenses/by/4.0/). 